\title{
Corrosion Inhibition of Zinc on HCl using Nypa fruticans Wurmb Extract and 1,5 Diphenyl Carbazone
}

\author{
${ }^{1 *}$ ORUBITE- OKOROSAYE, K; ${ }^{2}$ OFORKA, N C \\ ${ }^{1}$ Department of Chemistry, Rivers State University of Science \& Technology, Nkpolu, P. M. B. 5080, Port Harcourt, Nigeria \\ ${ }^{2}$ Department of Pure and Industrial Chemistry, P M. B. 5323, University of Port Harcourt, Port Hacourt, Nigeria
}

\begin{abstract}
The corrosion inhibition of zinc in hydrochloric acid by extract of Nypa Fruticans Wurmb was studied using weight loss techniques. Maximum inhibition efficiency (and surface coverage) was obtained at an optimum concentration. However increase in temperature decreased the inhibition efficiency at the temperature range studied. The inhibition action of Nypa Fruticans Wurmb extract compared closely to that of 1, 5 Diphenyl Carbazone (DPC). Optimum inhibition efficiency for zinc in the presence of Nypa Fruticans Wurmb extract was $36.43 \%$ and $40.70 \%$ with DPC. The phenomenon of physical adsorption has been proposed from the activation energy values $\left(19.33 \mathrm{~kJ} \mathrm{~mol}^{-1}\right.$ and $\left.21.11 \mathrm{~kJ} \mathrm{~mol}^{-1}\right)$ with Nypa Fruticans Wurmb extract and DPC respectively. A first order kinetics has been deduced from the kinetic treatment of the results. The heat of adsorption, $Q_{\text {ad }}$ range from ( -33.63 to - 58.52 $\mathrm{kJ}$ mo $\left.\mathrm{l}^{-1}\right)$ for both additives studied. Mean $\Delta \mathrm{G}_{\text {ads }}^{\circ}$ values $\left(-7.82\right.$ to $\left.8.68 \mathrm{~kJ} \mathrm{~mol}^{-1}\right)$ are negative and suggestive of adsorption on metal surface. The data obtained from this study fits well into the Langmuir isotherm. Evidence is hereby provided to show that Nypa Fruticans Wurmb extract and DPC inhibits the corrosion of zinc comparatively @ JASEM
\end{abstract}

Naturally occurring substances as inhibition of acid cleaning process has continued to receive attention as replacement for synthesized organic inhibitors. Investigation into the corrosion inhibition effects of some local plants (Ekpe et al 1994 and Loto 1998) have proposed parts of economic plants as pickling inhibitors. Not much has actually been achieved using these local plants, compared to the extensive research on synthesized organic inhibitors especially $\mathrm{N}$ - and S - containing organic compounds (Monticelli et al 1993 Ita and Offong 2000).

This study assesses the corrosion inhibition effect of the leaves of Nypa Fruticans Wurmb on the corrosion of zinc in hydrochloric acid medium. Nypa Fruticans Wurmb is of the family Arecaceae, a native of Asia and planted in Nigeria during the colonial administration. It grows abundantly along the coastal Nigeria. Nypa Fruticans Wurmb is highly utilized in other countries. Products are obtained from the leaves, the sap, fruit and stalk. Young shoots, decayed wood and buried roots or leaves find use as medicine in various parts of south Asia for herpes, toothache and head ache .The sap is a source of sugar about $14-17 \%$ of sucrose and organic acids and it is used to produce vinegar and alcoholic beverages in the Phillipines and Malaysia (Halos 1981). Nypa Fruticans Wurmb has not been extensively exploited in Nigeria. It's fast growing tendency is a continual threat to the more useful mangrove forest; hence the call for its eradication in some quarters (Ukoima 2000). This research work illustrates the similarity of

*Corresponding author the inhibition properties of Nypa Fruticans Wurmb to a synthesized organic inhibitor.

\section{EXPERIMENTAL}

Material Preparation: The zinc sheets used for this study $98 \%$ pure were mechanically press-cut into $5 \mathrm{x}$ $4 \mathrm{~cm}$ coupons of $1 \mathrm{~cm}$ thickness. The coupons were examined carefully to check for rough edges, which could influence the corrosion monitoring process. Surface treatment of the coupons was done by degreasing in absolute ethanol and drying in acetone. They were then stored in moisture free desiccators before use. Fresh leaves of Nypa Fruticans Wurmb were dried and ground into powder. $10 \mathrm{~g}$ of which was weighed into $100 \mathrm{ml}$ of $90 \%$ methanol in a $200 \mathrm{ml}$ volumetric flask. The flask was properly corked and left to stand for 48 hours with occasional shaking. The resultant mixture was filtered and methanol evaporated to dryness at $65^{\circ} \mathrm{C}$ in a water bath. This left a dark brown sticky residue, $0.5 \mathrm{~g}$ of which was weighed, dissolved in $100 \mathrm{ml}$ of ethanol and made up to $1000 \mathrm{ml}$ by $0.1 \mathrm{M} \mathrm{HCl}$ solution. This represents the stock solution from which different concentrations of $0.024,0.04$, and $0.08,0.16$ and $0.32 \mathrm{gdm}^{-3}$ were prepared by dilution with the same acid solution. Similar concentrations of DPC were also prepared. All reagents were of analar grade and doubly distilled water was used for the preparation of all solutions.

Weight loss corrosion test method: In the weight loss experiment, five $250 \mathrm{ml}$ beakers (in two sets) were labeled A, B, C, D and E containing 0.1, 0.5, 2.0, 2.5 
and $3.0 \mathrm{M} \mathrm{HCl}$ solutions were placed in a thermostated water bath maintained at 30 or $40{ }^{\circ} \mathrm{C}$. The zinc coupons were suspended in the beakers with the aid of glass hooks. The coupons were retrieved from their corrodent solutions at one hour material for 7 hours due to the high reactivity of zinc in $\mathrm{HCl}$ medium. Further measurements were carried out after introduction of the additives (Nypa Fruticans or DPC) in the beakers maintained at 30 or $40{ }^{\circ} \mathrm{C}$. They were retrieved from the medium at $1 \mathrm{hr}$ interval for 7 hours. Each set of coupons was dipped into saturated ammonium acetate solution at room temperature, to terminate the corrosion reaction. They were washed by scrubbing with a light brush and dried in acetone and finally in an oven maintained at $80{ }^{\circ} \mathrm{C}$. The weight loss of zinc coupons was evaluated in grams as the difference in the weight of the coupons before and after the test,

$$
\mathrm{W}=\left(\mathrm{Wi}-\mathrm{W}_{\mathrm{f}}\right) \mathrm{g}
$$

$\mathrm{JW}=$ weight loss of coupon, $\mathrm{Wi}=$ Initial weight of zinc coupon, $\mathrm{W}_{\mathrm{f}}=$ Final weight of zinc coupon. Each reading reported is an average of three experimental reading recorded to the nearest $0.0001 \mathrm{~g}$ on a santorium 3105 electronic balance. The inhibition efficiency of Nypa Fruticans wurmb extract or DPC acting as inhibitor was calculated using the formula,

$$
I . E \%=\left[1-\frac{W_{1}}{W_{2}}\right] \times 100
$$

(Ekpe et al 1994)
Where $\mathrm{w}_{1}$ and $\mathrm{w}_{2}$ are the weight losses (gms) for zinc in the presence and absence of additives respectively in $\mathrm{HCl}$ solution at the same temperature. The degree of surface coverage, $\theta$ is given by the equation, (Atkins 1980)

$$
\theta=1-\frac{W_{1}}{W_{2}}
$$

The corrosion rate of zinc in the different corrosion medium was determined for a 7 hours immersion period from weight loss using the formula' (NACE 1984)

$$
\text { Corrosion Rate }(\text { mdd })=\frac{534 w}{D A T}
$$

Where $\mathrm{w}=$ weight loss $(\mathrm{mg}) \mathrm{D}=$ density of specimen $(\mathrm{g} \mathrm{lcm}) \mathrm{A}=$ area of specimen $\left(\mathrm{cm}^{3}\right)$ and $\mathrm{T}$ is exposure time (hrs).

\section{RESULTS AND DISCUSSION}

Corrosion of zinc in $\mathrm{HCl}$ solution: Figure 1 shows the corrosion of zinc in different concentration of $\mathrm{HCl}$ at $30^{\circ} \mathrm{C}$ without additives. The result obtained indicates that the weight loss of zinc in $\mathrm{HCl}$ increased with increasing acid concentration. Similar trend was observed at $40^{\circ} \mathrm{C}$. This can be attributed to the fact that the rate of chemical reaction increases with increasing acid concentration and/or probably due to increase in the rate of diffusion and ionization of active species in the corrosion reaction. This conforms to reports by Omodudu and Oforka (1999).

\begin{tabular}{|c|c|c|}
\hline$+0.1 \mathrm{~m}$ & $=-0.5 \mathrm{~W}$ & $5 \mathrm{bl}$ \\
\hline
\end{tabular}

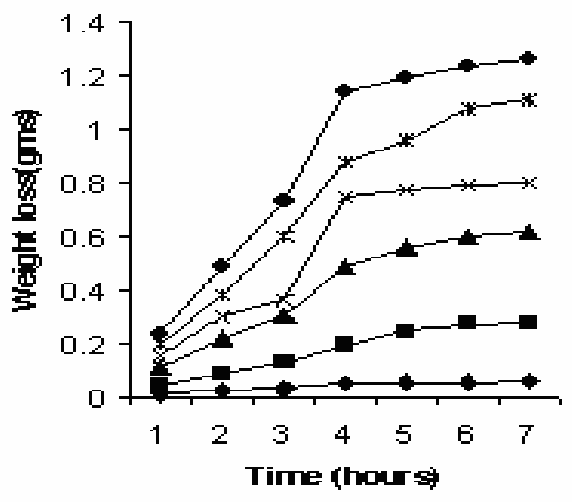

Fig. 1 variation of weight los whth time in different concentrations of $\mathrm{HCl}$ at $30 \mathrm{oC}$ without additwes. 
Table 2. Calculated values of activation energy $\mathrm{E}_{\mathrm{a}}\left(\mathrm{kJmol}^{-1}\right)$ Heat of Adsorption, $\mathrm{Q}^{\text {ad }}\left(\mathrm{kJmol}^{-1}\right.$ ) Rate constant , $\mathrm{k}$ (hours ${ }^{-1}$ ) Half life (hours) for zinc at 30 and $40^{\circ} \mathrm{C}$.

\begin{tabular}{|c|c|c|c|c|c|c|c|}
\hline System & Activation & Heat of & Rate col & $\mathrm{tt}, \mathrm{k}$ & Half life & & Average \\
\hline 0.32 & $\begin{array}{r}21.40 \\
(26.52)\end{array}$ & $\begin{array}{r}-32.33 \\
(-53.69)\end{array}$ & $\begin{array}{l}0.00125 \\
(0.00135)\end{array}$ & $\begin{array}{r}0.00164 \\
(0.00189)\end{array}$ & $\begin{array}{c}554.5 \\
(513.2)\end{array}$ & $\begin{array}{c}422.6 \\
(366.7)\end{array}$ & \\
\hline 0.16 & $\begin{array}{r}8.04 \\
(11.28)\end{array}$ & $\begin{array}{r}-4.14 \\
(-10.25)\end{array}$ & $\begin{array}{l}0.00121 \\
(0.00130)\end{array}$ & $\begin{array}{c}0.00134 \\
(0.00150)\end{array}$ & $\begin{array}{c}572.8 \\
(533.1)\end{array}$ & $\begin{array}{c}517.2 \\
(462.0)\end{array}$ & \\
\hline 0.08 & $\begin{array}{c}24.64 \\
(29.03\end{array}$ & $\begin{array}{r}-48.97 \\
(-54.43)\end{array}$ & $\begin{array}{l}0.00109 \\
(0.00139)\end{array}$ & $\begin{array}{r}0.00149 \\
(0.00172)\end{array}$ & $\begin{array}{r}635.9 \\
(493.4)\end{array}$ & $\begin{array}{c}465.2 \\
(402.9)\end{array}$ & \\
\hline 0.04 & $\begin{array}{c}18.96 \\
(22.22)\end{array}$ & $\begin{array}{r}-60.71 \\
(-66.22)\end{array}$ & $\begin{array}{l}0.00114 \\
(0.00132)\end{array}$ & $\begin{array}{c}0.00145 \\
(0.00175)\end{array}$ & $\begin{array}{c}608.0 \\
(525.1)\end{array}$ & $\begin{array}{c}478.0 \\
(396.0)\end{array}$ & \\
\hline 0.024 & $\begin{array}{r}6.04 \\
(16.50)\end{array}$ & $\begin{array}{r}-52.11 \\
(-58.92)\end{array}$ & $\begin{array}{r}0.00138 \\
(0.00146)\end{array}$ & $\begin{array}{c}0.00149 \\
(0.00180)\end{array}$ & $\begin{array}{c}502.2 \\
(497.0)\end{array}$ & $\begin{array}{c}465.1 \\
(385.1)\end{array}$ & \\
\hline $\begin{array}{l}\text { Average } \\
E_{a}\end{array}$ & $\begin{array}{c}19.33 \\
(21.11)\end{array}$ & & & & & & \\
\hline
\end{tabular}

Values in parenthesis are for DPC

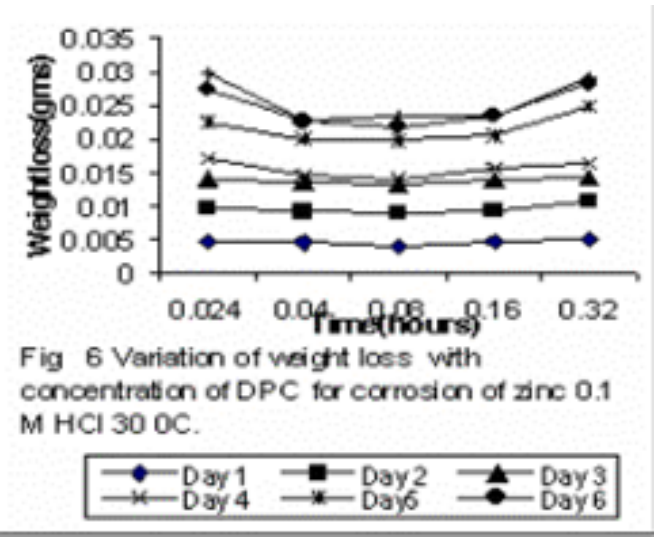

Hence at the end of the $7^{\text {th }}$ hour in $0.1 \mathrm{M} \mathrm{HCl}$, with Nypa Fruticans Wurmb extract concentration of $0.32 \mathrm{gdm}^{-3}$ weight loss of $0.0295 \mathrm{~g}$ per hour was obtained while for $0.08 \mathrm{gdm}^{-3}$ weights loss of $0.0253 \mathrm{~g}$ per hour was observed at $30^{\circ} \mathrm{C}$. Under similar conditions weight loss observed for $0.32 \mathrm{gm}^{-3}$ of DPC was $0.0291 \mathrm{~g}$ and $0.0236 \mathrm{~g}$ for $0.08 \mathrm{gdm}^{-3}$. Values of corrosion rates, inhibition efficiency follow similar trend (table 1). Percentage inhibition efficiency was higher at additives concentration of $0.08 \mathrm{dgm}^{-1}$ than at $0.32 \mathrm{gdm}^{-3}$ for both additives. This minimum corrosion rate at specific concentration may probably be due to the formation of a soluble complex on metal surface as in the case of polyphosphates or as a result of protonation of additive molecules and subsequent acceleration of the hydrogen evolution process (Moore 1994). At higher temperature of $40^{\circ} \mathrm{C}$ maximum inhibition efficiency was obtained at additives concentration of $0.16 \mathrm{gdm}^{-3}$. This shift may be due to the adsorption of more inhibitor molecules on the metal surface.
However inhibition decreases with increase in temperature. The maximum inhibition efficiency is lower at $40{ }^{\circ} \mathrm{C}$ than at $30{ }^{\circ} \mathrm{C}$. This is in agreement with what is known about the dependence of adsorption on temperature that as temperature rises, the quantity adsorbed decreases and as a result, the isotherm of higher temperatures are below the isotherm of lower ones. It is of generally view that inhibition of metals in acidic solution results from the adsorption of molecules or ions of the inhibitor on the metal surface The action of organic inhibitors depends on the type of interaction between the substance and the metallic surface. This could cause a change either in the electrochemical process mechanism or on the surface available to the process. The decrease in inhibition efficiency with increasing temperature, suggest weak adsorption interaction between zinc surface and the additives, which is physical in nature (Talati and Modi 1998).

In order to further support the assertion that physical adsorption is proposed, the values of 
activation energy $\left(E_{a}\right)$ were calculated using the integrated form of the Arrhenius equation.

$$
\log \frac{K_{2}}{K_{1}}=\frac{E_{a}}{2.303 R}\left[\frac{1}{T_{1}}-\frac{1}{T_{2}}\right]
$$

Where $\mathrm{K}_{1}$ and $\mathrm{K}_{2}$ are rate constants at $\mathrm{T}_{1}$ and $\mathrm{T}_{2}$ respectively. The values are presented in Table 2 . The low values recorded suggest physical adsorption (Barrow, 1993).

From the corrosion rates or surface coverage $(\theta)$ for different inhibitor concentrations the respective adsorption isotherms can be obtained.

The surface coverage data (table 1) fits into the Langmiur isotherm given as,

$$
\frac{C}{\theta}=\frac{1}{b} \times C
$$

Where $\mathrm{C}$ is concentration of additives. With either additive, it was shown (figure not given) that corrosion inhibition of zinc obeys the Langmiur isotherm. Hence the mechanism of inhibition may be due to the formation and maintenance of a protective film on the metal surface. The plots further suggest that both additives (Nypa Fruticans wurmb extract and DPC) cover both the anodic and cathodic regions through general adsorption following Langmiur isotherm.

\section{Kinetic/Thermodynamic Treatment of weight loss results}

Corrosion reaction is an overall reaction in which both solid and liquid phases are consumed. It is therefore difficult to apply most of the principles of chemical kinetics to corrosion reaction. Plots of $\log$ $\mathrm{w}_{\mathrm{f}}$ against time in hours at $30^{\circ} \mathrm{C}$ in $\mathrm{HCl}$ for the different systems studied reveal linear plots signifying first- order kinetics. The values of rate constant $(\mathrm{k})$ in table 2 were obtained from this plot. Similar plots were obtained at $40^{\circ} \mathrm{C}$. This conforms to observations (Ibok et al 1994 and Ekpe et al 1994).

The values of heat of adsorption $\mathrm{Q}_{\mathrm{ad}}$ were calculated using the following equation,

$$
Q_{a d}=2.303 R \log \left[\frac{\theta_{2}}{1-\theta_{2}}\right]-\log \left[\frac{\theta_{1}}{1-\theta_{1}}\right] \times \frac{T_{1} T_{2}}{T_{2}-T_{1}}
$$

Where $\theta_{1}$ and $\theta_{2}$ are degrees of surface coverage at temperature $T_{1}$ and $T_{2}$ by the different additives. From Table 2 it is evident that in all the cases, the $\mathrm{Q}_{\mathrm{ad}}$ values are negative and range from $-4.14 \mathrm{kJmol}^{-1}$ to - $60.71 \mathrm{kJmol}^{-1}$ with Nypa Fruticans extract and $10.25 \mathrm{kJmol}^{-1}$ and $-66.22 \mathrm{kJmol}^{-1}$ for DPC as inhibitor. The negative $Q_{a d}$ values also show that the adsorption and the inhibition efficiency decrease with temperature. $\Delta \mathrm{G}_{\text {ads }}^{0}$ values were obtained with the help of the equation, $\log C=\log \left[\frac{\theta_{1}}{1-\theta_{1}}\right]-\log B$

Where $\log \mathrm{B}=-1.74-\left(\Delta \mathrm{G}^{0}{ }_{\text {ads }} / 2.303 \mathrm{RT}\right)$ and $\mathrm{C}$ $=$ additives concentrate

The values are presented in table 2.The negative values suggest strong adsorption on zinc's surface. As temperature increases the value of $\Delta \mathrm{G}^{0}$ ads increases while percentage inhibition efficiency decreases. It is of note that $\Delta \mathrm{G}^{0}{ }_{\text {ads }}$ up to $-20 \mathrm{kJmol}^{-1}$ are consistent with electrostatic interaction between charged molecules and the charged metal (physical adsorption) while $\Delta \mathrm{G}^{0}{ }_{\text {ads }}$ values more negative that $40 \mathrm{kJmol}^{-1}$ involve charge sharing or transfer from the inhibitor molecules to the metal surface to form a coordinate bond (chemisorption).

The half life $\left(\mathrm{t}^{1} / 2\right)$ values were calculated using the equation (Atkins 1980)

$t_{1 / 2}=\frac{0.693}{k}$

Half-life increases with increase in concentration of Nypa Fruticans wurmb extract or DPC, while the rate constant $\mathrm{K}$, decreases with increase in concentration.

Comparative study of inhibition efficiencies of Nypa Fruticans wurmb and DPC show that they exhibit similar inhibition properties. From the result of weight loss against time, corrosion rate, half-life for both additives metal dissolution was inhibited to a comparative degree. The inhibition action of leaves, fruits, bark of trees and plant has been attributed to tannins (Loto 1998) and nitrogenous compounds in the extracts. The molecular structure of DPC reveals an amine type organic compound with nitrogen and phenyl groups. Both group have been found effective for corrosion inhibition and inhibitors of high molecular weight (carbon atom 12 and above) are better inhibitors than the methyl derivative (Finley and Hackerman 1960).

It may be reasonable to suggest that corrosion inhibition by both additives may be due to bulky nitrogenous organic compound or tannins, $k$ Jhhod ${ }^{-1}$ contain polar groups. For Nypa fruticans extract, these may have effected inhibition through nitrogen bond on metal surface with the formation of Nypa $-\mathrm{Zn}^{2+}$ complex on the surface of the metal. Nitrogen atoms adsorbed on the metal surface through an unshared pair of electron may be responsible for film formation in DPC.

\section{Conclusion}

Nypa Fruticans Wurmb leaves extract and DPC inhibit the corrosion of zinc comparatively. Inhibition though generally low was maximum at an optimum concentration and low temperature. This may be due to protonation of the hydrogen evolution process or 
the formation of a soluble complex on zinc surface by molecules of Nypa Fruticans Wurmb or DPC.

\section{REFERENCES}

Atkins, P W (1980), Chemisorbed and physisorbed species, A textbook of physical chemistry, (University Press Oxford) 936-938.

Barrow, G.M. (1983). Physical chemistry, Mc GrawHill, New York, $4^{\text {th }}$ edition 1988. 739.

Corrosion Basics; An introduction, NACE (1984).

Ekpe, U.J., Ebenso, E.E., Ibok, U. J.,(1994) Inhibitory action of Azadirachta indica leaves extract on corrosion of mild steel in tetraoxosulphate (vi) acid dissolution of metals. J. W Afri. Sci Assoc. 37, 13-30.

Finley, H. F; and Hackerman, A. (1960). Effect of adsorption of polar organic inhibitors in acid dissolution of metals. Ind. Eng. Chem., 46, 523

Halos, S. C (1981). Nypa for alcogas production. Canopy 7:51.6

Ibok, U.J; Ekpe, U. J; and Ita, O. E (1994). Inhibition action of methyl and phenyl thiosemicarbazone derivatives on mild steel corrosion in hydrochloric acid . Mat. Chem. And Phy. 40, 63.
Ita, B, I and Effiong, O. E (2000 ). Inhibition of mild steel corrosion in $\mathrm{HCl}$ by 2- Aminopyridine and 2- (Aminomethyl) pyridine.Global Journal of Pure and Applied Sciences, 6, 1, 51-53.

Loto, C.A (1998). The effect of veronia Amydalina (bitter leaf) extracts on corrosion inhibition of mild steel in $0.5 \mathrm{M} \mathrm{HCl}$ and $\mathrm{H}_{2} \mathrm{SO}_{4}$ solution. Nig. Corr. Journal, vol. 1 (1), 19-20.

Monticelli, C. Frignani, A., Brunoro, G; Trabanelli, G; Zucchi, F and Tassinari, M;(1993). Corrosion inhibition of steel in alkaline chloride solutions Corrosion Science. 35:1483-1489.

Moore, J,J. (1994). Corrosion of Metals. A textbook of chemical metallurgy, (ButterworthHeinemann) Ltd. 351-393.

Omo-dudu, D.U. and Oforka, N.C. (1999). Inhibition of the corrosion of mild steel in Trioxonitrate (v) acid. Nig. Journal of phy. 2, 148-153.

Ukoima, H.N. (2000). Bioversity reservation of Nypah palm extermination or utilization. A paper presented at the $7^{\text {th }}$ annual conference of Nig. Soc. of Bio. Conservation 